\title{
Refractive Error in Juvenile Patients Presenting with Nystagmus at Tertiary Care Hospital of Karachi
}

Kanwal Perveen, Nasir Ahmed, Khalida Perveen, Tauseef Mehmood

- - - - - - - - - - - - - - - - - - - - - - - - - - - ABSTRACT

Objective: To evaluate the types of refractive errors in nystagmus patients among the age (5-15 years) patients.

Study Design and Setting: An observational cross-sectional study was conducted at Pediatric department of Al-Ibrahim Eye Hospital, Karachi from June 2018 to March 2019.

Methodology: A total of 55 patients (110 eyes) were selected from study setting. The protocol for examination for all patients were evaluated at the special clinic of Orthoptics includes the demographic data, educational status, history of onset, type of nystagmus. The anterior segment was examined with a slit-lamp to exclude any other ocular disease. Orthoptic assessment includes cover uncover test, Hirschberg, ocular motility, prism cover test and pupillary reflex test, to observe any associated deviation. All the patients were examined after obtaining a fully informed consent. After the proper diagnosis of nystagmus patient was recruited as per inclusion and exclusion criteria with no restrictions of gender. All the observations were noted on a Proforma, Data analysis was done by using SPSS version 20 . P-value $<0.05$ was considered as statistically significant.

RESULTS: A total of 55 patients, 29 male (52.7\%) and 26 female (47.3\%) were selected. This study shows out of 55 patients (110 eyes), 46 (42\%) eyes had myopic astigmatism, while 33 (30\%) eyes were found hyperopic astigmatism, 20 $(18 \%)$ eyes were observed hyperopic and $11(10 \%)$ eyes were observed myopic.

CONCLUSION: Most common type of refractive error in nystagmus was myopic astigmatism. The refractive correction should be encouraged in children with nystagmus; improvement in visual function is likely to occur.

KEYWORDS: Oscillation, Pendular Nystagmus, Refractive error

\section{How to cite this Article:}

Perveen K, Ahmed N, Perveen K, Mehmood T. Refractive Error in Juvenile Patients Presenting with Nystagmus at Tertiary Care Hospital of Karachi. J Bahria Uni Med Dental Coll. 2021; 11(3):112-115 DOI: https://doi.org/10.51985/ZDVZ6566

This is an Open Access article distributed under the terms of the Creative Commons Attriution Non Commercial Liciense (http:// creativecommons/org/licences/by-nc/4.0) which permits unrestricted non commercial use, distribution and reproduction in any medium, provided the original work is properly cited.

\section{INTRODUCTION:}

Nystagmus is a congenital or acquired uncontrolled eye movement results in vision loss. Also known as dancing eye". OR oscillating eye movement with rhythm is known as nystagmus. ${ }^{1,2}$ Types of oscillations, pendular nystagmus may be due to sinusoidal oscillations in which equal amplitude and velocity of movement occurs, jerk nystagmus in which a sluggish starting phase and a fast corrective phase. ${ }^{3}$ In physiologic nystagmus minimized retinal image slip, where the slow phases of nystagmus is present but the slow phases

Kanwal Perveen
Lecturer/Optometrist,
Isra School of Optometry/ Al-Ibrahim Eye Hospital
Email: kanwalyaqoob16@gmail.com
Nasir Ahmed
Assistant Professor,
Isra Postgraduate Institute of Ophthalmology
Khalida Perveen
Optometrist, Al-Ibrahim Eye Hospital
Tauseef Mehmood
Itatistician, Isra School of Optometry
Received: 17-12-2020
Accepted: 14-06-2021

of pathologic nystagmus cause maximum retinal image slip. Greater than 5 degree Retinal image slip of per second produces a decline in visual acuity. ${ }^{4,5}$ In study of United Kingdom shows developed rate of occurrence of nystagmus in white Europeans than Asians. The prevalence of nystagmus in the general population was estimated to be 24.0 per 10,000 populations. ${ }^{6}$ The study based on mass screening in china shows prevalence of congenital nystagmus was $1: 1404$. $^{7}$ Nystagmus was found to be a leading cause of low vision in study sample comprising of 504 individuals. ${ }^{8}$ There are three main mechanism of eye movement control: fixation, the vestibulo-ocular reflex and gaze holding system. Any disorders which cause failure in any of these will results in nystagmus. ${ }^{9}$ There are three forms of nystagmus Infantile: Most often develops by 2 to 3 months of age, Spasmus nutans: It usually occurs between 6 months and 3 years of age and improves on its own between 2 and 8 years of age. Acquired: Develops later in childhood or adulthood. ${ }^{10}$ An error in the focusing of light by the eye is known as refractive error. ${ }^{11}$ Uncorrected refractive error caused estimated a total of 153 million people visually impaired. ${ }^{12}$ In a retrospective data of 47 medical records of children with infantile nystagmus syndrome spherical equivalent of Hypermetropic refractive error was mostly found. ${ }^{13}$ A study in 2010 data 
shows with the rule astigmatism was predominant in children with infantile nystagmus syndrome. ${ }^{14}$ This study will help us to identify the most frequent occurring refractive error in patients with nystagmus as related studies have not been conducted yet in the Sindh province. Therefore; the purpose of this study was to evaluate the types of refractive errors in nystagmus patients among the age (5-15 years).

\section{METHODOLOGY:}

This was a cross-sectional study carried out at Pediatric department of Al-Ibrahim Eye Hospital, Karachi from June 2018 to March 2019. Prior Ethical approval was taken from the Institute Research Ethical Committee. A non- probability convenience sampling method was used to collect data. Sample size was calculated from WHO calculator by taking statistical formulation of $95 \%$ confidence interval and $5 \%$ margin of error. The sample size was determined by formula was 110 . A total of 55 patients (110 eyes) were selected from patient attending Paediatric Department of Al-Ibrahim Eye Hospital, Karachi. The protocol for examination for all patients were evaluated at the special clinic of Orthoptics includes the demographic data, educational status, history of onset, type of nystagmus. The anterior segment was examined with a slit-lamp to exclude any other ocular disease. Orthoptic assessment includes cover uncover test, Hirschberg, ocular motility, prism cover test and pupillary reflex test, to observe any associated deviation. All patients were examined and data was recorded after obtaining a fully informed consent from their guardian and data confidentiality was ensured. After the proper diagnosis of nystagmus patient was selected with inclusion and exclusion criteria with no restrictions of gender. Age group was 5-15 years was followed. Exclusion criteria were any ocular surgery that may cause nystagmus, pseadophakic, Aphakic and patients with other ocular pathologies and degenerations. All the observations were noted on a proforma, Cycloplegic refraction was done in both eyes of one participant and 3 drops of cyclopentolate eye drop were administrated and then later Retinoscopy was performed to assess the types of refractive error in nystagmus patients. In Proforma researcher recorded age of patient, gender of patient, onset of nystagmus, type of nystagmus and wave form of nystagmus. The collected data was analyzed from the software SPSS version 20.0 Frequencies and percentages were calculated for the categorical variables. Different statistical charts were presented for several categorical data. P-value $<0.05$ was considered as statistically significant.

\section{RESULTS:}

A total of 55 patients (110 eyes) were selected on the basis of the inclusion and exclusion criteria of the study, from which 58(eyes) were of male (52.7\%) and 52 (eyes) were of female (47.3\%), both genders, all having nystagmus. The age group was divided into two categories (5 to 10 years) and ( $>10$ to 15 years), from age group (5 to 10 years) 10
(91\%) eyes were found as myopic, $13(65 \%)$ eyes were hyperopic, 35 (76\%) eyes were myopic astigmatism and $24(73 \%)$ eyes were hyperopic astigmatism, while in age group (>10 to 15 years), 1 (9\%)eye were myopic, 7 (35\%) eyes were hyperopic, 11(24\%) eye were myopic astigmatism and $9(27 \%)$ eyes were hyperopic astigmatism. In comparison of onset of nystagmus out of 55 patients only 3 patients 6 eyes $(5 \%)$ had acquired whereas 52 (104 eyes, 95\%)patients had congenital nystagmus. In patients with congenital nystagmus, $11(100 \%)$ eyes were found as myopic, 20 (100\%) eyes were hyperopic, 42 (91\%) eyes were simple myopic astigmatism, and 31 (94\%) eyes were hyperopic simple astigmatism. In manifest type of nystagmus less common refractive error was myopia. From which $11(100 \%)$ eyes were myopic, 18 (90\%) eyes were hyperopic, 42 (91\%) eyes were compound myopic astigmatism and $29(88 \%)$ eyes were simple hyperopic astigmatism.

While in latent type of nystagmus there were no Patient found with simple Myopic but $2(10 \%)$ eyes were hyperopic, $4(9 \%)$ eyes were compound myopic astigmatism and 4 (12\%) eyes were compound hyperopic astigmatism.

According to waveform of nystagmus in jerky $11(100 \%)$ eyes were myopic, 20 (100\%) eyes were hyperopic, 46 $(100 \%)$ were myopic astigmatism and $33(100 \%)$ eyes were hyperopic astigmatism while there were no eyes with pendular waveform nystagmus.

Table 1: Demographic Characteristics

\begin{tabular}{|c|c|c|}
\hline Age (Years) & Frequency & Percentage \\
\hline $5-10$ & 41 & $74.5 \%$ \\
\hline $11-15$ & 14 & $25.5 \%$ \\
\hline Total & 55 & $100.0 \%$ \\
\hline Gender & Frequency & Percentage \\
\hline Male & 29 & $52.7 \%$ \\
\hline Female & 26 & $47.3 \%$ \\
\hline Total & 55 & $100.0 \%$ \\
\hline Education & Frequency & Percentage \\
\hline Un-Educated & 38 & $69.1 \%$ \\
\hline Primary & 16 & $29.1 \%$ \\
\hline Secondary & 1 & $1.8 \%$ \\
\hline Total & 55 & $100.0 \%$ \\
\hline
\end{tabular}

Figure 1: Types of Nystagmus Onset ( $\mathrm{n}=110$ eyes)

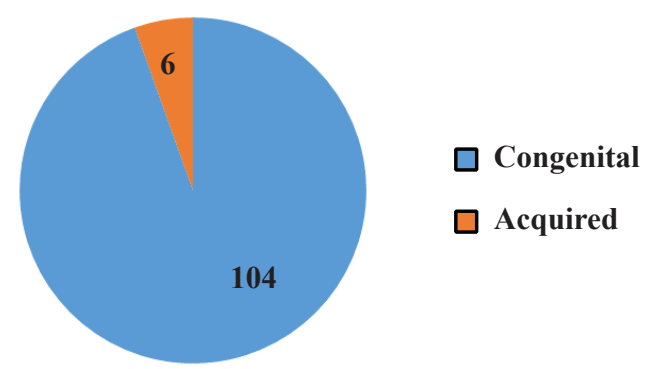


Figure 2: Type of Nystagmus ( $\mathrm{n}=110$ eyes)

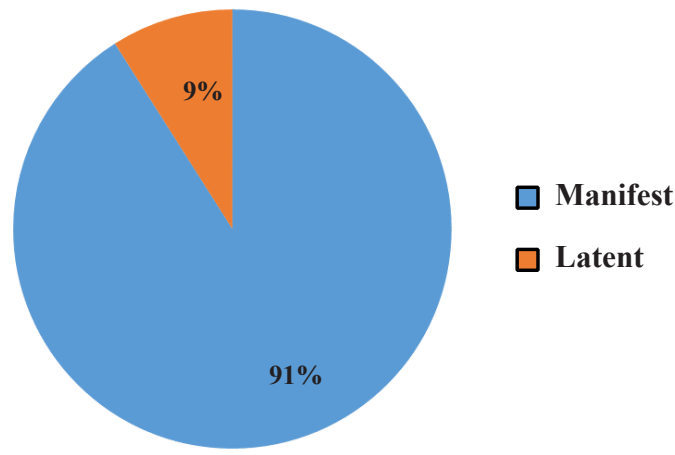

Figure 3: Type of Refractive Error ( $\mathrm{n}=110$ eyes)

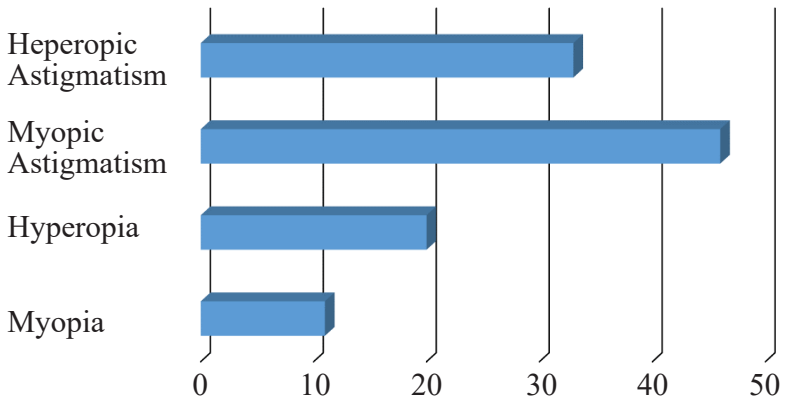

Table-2: Distribution of Type of Refractive Error and Age

\begin{tabular}{|c|c|c|c|c|}
\hline \multirow{2}{*}{$\begin{array}{c}\text { Type Of Refractive } \\
\text { Error }\end{array}$} & \multicolumn{2}{|c|}{$\begin{array}{c}\text { Age of patient } \\
\text { (years) }\end{array}$} & \multirow[t]{2}{*}{ Total } & \multirow[t]{2}{*}{ P-value } \\
\hline & 5 to 10 & 11 to 15 & & \\
\hline \multirow{2}{*}{ Myopia } & 10 & 1 & 11 & \multirow{10}{*}{0.479} \\
\hline & $12.2 \%$ & $3.6 \%$ & $10.0 \%$ & \\
\hline \multirow{2}{*}{ Hyperopia } & 13 & 7 & 20 & \\
\hline & $15.9 \%$ & $25.0 \%$ & $18.2 \%$ & \\
\hline \multirow{2}{*}{ Myopic Astigmatism } & 35 & 11 & 46 & \\
\hline & $42.7 \%$ & $39.3 \%$ & $41.8 \%$ & \\
\hline \multirow{2}{*}{ Heperopic Astigmatism } & 24 & 9 & 33 & \\
\hline & $29.3 \%$ & $32.1 \%$ & $30.0 \%$ & \\
\hline \multirow{2}{*}{ Total Eyes } & 82 & 28 & 110 & \\
\hline & $100.0 \%$ & $100.0 \%$ & $100.0 \%$ & \\
\hline
\end{tabular}

\section{DISCUSSION:}

This study was to evaluate the types of refractive errors in nystagmus patients among the age (5-15 years). A study in 2011 data showed Out of total 170 Down Syndrome patients Nystagmus was observed in 18 patients. ${ }^{15}$ Children with nystagmus had greater association of Myopia and astigmatism $^{16}$. Some studies shows increment in Astigmatism with age ${ }^{17}$ caused by constant oscillations of the eyeball. ${ }^{14}$ It is suggested to give full correction which can help in better distinguish horizontal stimuli than vertical ones. ${ }^{13}{ }^{18}{ }^{19}$
This study shows out of $\mathrm{n}=55$ patients 110 eyes $(100 \%)$, $\mathrm{n}=46(42 \%)$ eyes had myopic astigmatism, while $\mathrm{n}=33$ $(30 \%)$ eyes were found hyperopic astigmatism, $n=20(18 \%)$ eyes were observed hyperopic and $n=11(10 \%)$ eyes were observed myopic. Similar studies have been reported by researchers before but none in province Sindh. Study is done on patients having Down syndrome. Astigmatism was present in $72.4 \%$ of patients of Down syndrome. ${ }^{11}$ Nystagmus was observed in 18 patients having Down Syndrome. ${ }^{11}$ In another study showed slightly myopic in children adolescent and adults with idiopathic congenital nystagmus. There was more astigmatism in the albino (Albinism is inherited conditions in which there is a lack of pigmentation in the eyes and usually in the skin and hair as well) group (primarily with-the-rule; where the vertical meridian is steepest). ${ }^{14}$ While In other study adolescent and adults myopic in albinos were less than idiopathic Congenital Nystagmus, ${ }^{14-20}$ but in this recent study it no difference was found in type of refractive error result but study sample size was different. In our study only $\mathrm{n}=20$ eyes were found hypermetric. While a Prospective study shows Hypermetropia is the most predominant error in the Infantile Nystagmus Syndrome. ${ }^{9}$ In this study $\mathrm{n}=11$ eyes had myopia which show low occurrence of myopia but as compare to European study the occurrence of myopia and astigmatism (especially with-therule astigmatism) was greater in children with nystagmus. ${ }^{10,15}$

\section{CONCLUSION:}

Most common type of refractive error in nystagmus was myopic astigmatism. The refractive correction should be encouraged in children with nystagmus; improvement in visual function is likely to occur.

\footnotetext{
Authors Contribution:

Kanwal Perveen: Conceived the study, Manuscript writing, I Proforma development, correspondence in replying reviews I of manuscript \& Final review

Nasir Ahmed: Manuscript writing, Designing the study, I Proforma development, Data collection \& Final Review

I Khalida Perveen: Help in Manuscript writing

I Tauseef Mehmood: Designing the study, Statistical Analysis I

Help in Methodology, Proforma development, Data collection

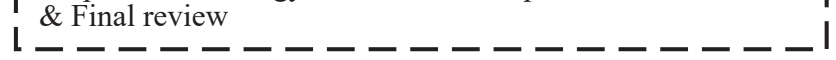

\section{REFERENCES:}

1. Laroumagne S, Elharrar X, Coiffard B, Plojoux J, Dutau H, Breen D, Astoul P. "Dancing eye syndrome" secondary to opsoclonus-myoclonus syndrome in small-cell lung cancer. Case reports in medicine. 2014; 23:2014.

2. Gale Encyclopedia of Medicine. Copyright 2008 The Gale Group, Inc.

3. Rucker JC. An update on acquired nystagmus. Semin Ophthalmol 2008;23(2):91-7.

4. Thurtell MJ, Leigh RJ. Treatment of nystagmus. Semin Neurol. 2015;35(5):522-6. 
5. Dunn MJ, Margrain TH, Woodhouse JM, Ennis FA, Harris $\mathrm{CM}$, Erichsen JT. Grating visual acuity in infantile nystagmus in the absence of image motion. Investigative ophthalmology \& visual science. 2014;55(4):2682-6.

6. Sarvananthan N, Surendran M, Roberts EO, Jain S, Thomas S, Shah N, Proudlock FA, Thompson JR, McLean RJ, Degg C, Woodruff G. The prevalence of nystagmus: the Leicestershire nystagmus survey. Investigative ophthalmology \& visual science. 2009;50(11):5201-6.

7. D N Hu. Prevalence and mode of inheritance of major genetic eye diseases in China. J Med Genet. 1987; 24(10):584-588

8. Shah M, Khan MD. Causes of low vision amongst the lowvision patients attending the Low-Vision Clinic at Khyber Institute of Ophthalmic Medical Sciences (KIOMS), Hayatabad Medical Complex Peshawar, Pakistan. Visual Imp Res. 2004;6(2-3):89-97

9. Richard V Abadi. Mechanisms underlying nystagmus. J R Soc Med 2002; 95(5):

10. American optometric association. Nystagmus. https://www.aoa.org/healthy-eyes/eye-and-visionconditions/nystagmus?sso=y (accessed 5 May 2021).

11. world health organization. Blindness and vision impairment: Refractive errors. https://www.who.int/news-room/q-adetail/blindness-and-vision-impairment-refractive-errors (accessed 22-4-2021).

12. Serge Resnikoff, Donatella Pascolini Silvio P Mariotti \& Gopal P Pokharel. Global magnitude of visual impairment caused by uncorrected refractive errors in 2004. Bulletin of the World Health Organization 2008; 86
13. Healey N, McClelland JF, Saunders KJ, Jackson AJ. Longitudinal study of spherical refractive error in infantile nystagmus syndrome. Ophth and Physio Optics. 2014;34(3):369-75

14. Wang J1, Wyatt LM, Felius J, Stager DR Jr, Stager DR Sr, Birch EE, Bedell HE. 'Onset and progression of with-the-rule astigmatism in children with infantile nystagmus syndrome.' National Library of Medicine National Institutes of Health, 2010 Janaury5(1), pp. 594-601.

15. Ljubic A, Trajkovski V, Stankovic B. Strabismus, refractive errors and nystagmus in children and young adults with Down syndrome. Ophthalmic gen. 2011;32(4):204-11

16. Fledelius HC, Jensen $\mathrm{H}$. Infantile nystagmus and visual deprivation: foveal instability and refractive development in a low vision register series. European j ophth. 20141;24(4):59907

17. Dickinson CM, Abadi RV. Corneal topography of humans with congenital nystagmus. Ophthalmic Physiol Opt. 1984;4(1):3-13.

18. Abadi RV, Bjerre A. Motor and sensory characteristics of infantile nystagmus. Br J Ophthalmol. 2002;86(10):1152-1160.

19. Bedell HE, Loshin DS. Interrelations between measures of visual acuity and parameters of eye movement in congenital nystagmus. Invest Ophthalmol Vis Sci. 1991;32(2):416-421.

20. Moshkovitz A, Lev M, Polat U. Monocular and Binocular temporal Visual perception of infantile nystagmus. Scientific reports. 2020 Mar 18;10(1):1-4. 